\title{
Cadenas productivas y redes de acción colectiva en Medellín y el Valle de Aburrá
}

\author{
María Soledad Betancur * \\ Omar Alonso Urán Arenas ** \\ ÁNGELA STIENEN ***
}

\begin{abstract}
The aim of this paper is to present the way in which territorial development and reconfiguration in an urban context, such as the Metropolitan Area of Medellin and Aburrá Valley, is the result of a complex process in which the economic logic of the enterprise actors interacts with the social and political logic of other actors, when they interact in different scenarios and collective action networks. In this scenarios and networks, the intention is to create the discursive conditions -that legitimate and regulate the labour transformations and the social structure that enables new and less expensive productive strategies. In particular, we focus on the issue of economic and social sustainability of territory reconfiguration resulting of that interaction, and whether it produces, or not, enough economic diversification and social implications that allow to confront the contingencies and threats of a changing global environment.
\end{abstract}

Keywords: economic geography, productive chains, collective actions, urban territory reconfiguration, regional urban development.

\section{Resumen}

Este trabajo busca exponer cómo el desarrollo y la reconfiguración territorial de un entorno urbano-regional como lo es el área metropolitana de Medellín y el Valle de Aburrá es resultante de un proceso complejo en el que interactúan la lógica económica de los actores empresariales con la lógica política y social de otros actores a partir de su encuentro e interacción en diferentes escenarios y redes de acción colectiva, en las que se busca crear, tanto las condiciones discursivas que legitimen y regulen las transformaciones laborales, como los tejidos sociales que faciliten nuevas y menos costosas estrategias productivas. En particular, nos preguntamos por la sostenibilidad económica y social de la configuración territorial resultante de dicha interacción, en la medida que genere o no la suficiente diversificación económica e implicación social que le permita hacer frente a las contingencias y amenazas de un medio global tan cambiante como el actual.

Palabras clave: geografía económica, cadenas productivas, acción colectiva, reconfiguración territorial urbana, desarrollo urbano-regional.

* Universidad de Antioquia, Colombia. Correo-e: ccp@corporacionpp.org.co

* Universidad de Antioquia, Colombia. Correo-e: ipc@corporacionpp.org.co

*** Universidad de Berna, Suiza. Correo-e: stienen@ethno.unibe.ch 


\section{Introducción ${ }^{1}$}

Para este trabajo asumimos que los territorios, en cuanto espacios socialmente construidos, pueden desaparecer o reconfigurarse, bien sea por dinámicas internas o por transformaciones en su entorno. En el nuevo contexto político, productivo y comercial de la globalización las nuevas formas de reconfiguración territorial competitiva se expresan, fundamentalmente, en la capacidad de los grupos y actores sociales de configurarse y expresarse como territorios autoconstituidos internamente e imbricados en las dinámicas globales. La existencia o falta de esta capacidad de autonomía territorial imbricada (Repetto, 1998), apertura estratégica hacia el entorno global y articulación significativa de la diversidad interna, constituye la riqueza o pobreza fundamental, en términos de sostenibilidad y resiliencia de una determinada espacialidad social existente.

El modo de regulación asociado con el régimen de acumulación de un territorio en el actual contexto de globalización que implica un debilitamiento del Estado-Nación y la emergencia de lo local y regional, sólo es posible comprenderse en la identificación de la interacción entre las redes de capital y producción, por un lado, y con las redes sociales y políticas por el otro. Por lo tanto no es recomendable asumir el análisis territorial desde la linealidad de la cadena productiva o desde la mera acción social o las políticas públicas.

Nuestras preguntas básicas de partida han sido: ¿̇e autorregula la expansión urbana sólo desde la dinámica del mercado, o es regulada en parte por las lógicas de los actores que lo intervienen?, ¿quiénes son esos actores, cómo operan y cómo se interrelacionan?, ¿qué proyecto de desarrollo regional se teje alrededor de estas interacciones?

Buscamos mostrar cómo ha sido la evolución de la actividad productiva del entorno urbano regional del Valle de Aburrá en los últimos treinta años en dos acápites: el primero se refiere a la relación entre cadenas productivas y reconfiguración territorial, haciendo especial énfasis en el proceso de expansión territorial explicado por las tendencias de desconcentración productiva y que abarca lo que llamamos tres trayectorias de desconcentración; hacia el oriente antioqueño, al interior del mismo Valle de Aburrá y una mirada a la ciudad de Medellín. El segundo es ver

${ }^{1}$ Una versión preliminar de este trabajo fue presentada en el vi Seminario de la Red Iberoamericana de Globalización y Territorio, en Rosario, Argentina, mayo de 2001. 
de qué manera se ha regulado esta transformación y expansión, tejida de un lado por las redes de capital y de otro por la interacción de otras instituciones y actores que se mueven en la región.

Y por último, a manera de conclusiones, estableceremos las relaciones entre los componentes anteriormente analizados, buscando indagar por su lógica y dinámica sistémica y estructural en términos de la configuración territorial y el modelo de desarrollo producido por la interacción entre dinámicas económico-productivas y capital social.

\section{Síntesis de referentes teóricos}

En este trabajo pretendemos hacer una lectura del territorio definido como área metropolitana del Valle de Aburrá, tratando de descubrir la interacción entre cadenas productivas y redes de acción colectiva. Para lograrlo, hemos tomado como categoría de referencia el modelo de desarrollo territorial, éste lo entendemos como una formación social histórica en la que, en un espacio biofísico concreto, se dan procesos de producción y reproducción material y simbólica del género humano, con énfasis en el proceso de regulación de autoproducción de dicha formación social. Ello implica tener en cuenta una serie de elementos o subsistemas, que en su interacción estructuran y dan sustento al modelo de desarrollo territorial, así como en cuanto a la expresión y despliegue dinámico de la integración y desintegración social y sistémica de sus componentes individuales y colectivos. Estos elementos estructurantes son básicamente los siguientes:

- Un paradigma industrial, como articulación entre un esquema tecnológico básico y una forma de organización del trabajo (Lipietz, 1991);

- Un régimen de acumulación, en cuanto a quiénes y cómo se apropian del excedente económico y productivo (Lipietz, 1991);

- Un modo de regulación, en tanto administración sociopolítica de las tensiones y conflictos inherentes a la relación capital-trabajo, referida en las relaciones salariales, los vínculos y conflictos entre los capitalistas y el papel que juegan allí las instituciones que regulan la existencia de lo social (Lipietz y Leborgn, 1991; Putnam, 1994; Fukuyama, 1998);

- Una configuración socioespacial, asociada con las dotaciones biofísicas e infraestructura territorial donde se expre- 
san parte de las condiciones ambientales de existencia, y en torno a la cual se desenvuelve parte de la conflictividad de la región (Méndez, 1997).

Traduciendo lo anterior al espacio concreto de nuestro análisis, ha significado:

- Observar las lógicas y rupturas de la configuración evolutiva de las relaciones de capital económico y trabajo y su impacto sobre el territorio, a partir de un seguimiento a las formas dominantes de producción y sus tendencias de localización en el Valle de Aburrá y su entorno regional.

- Tener en cuenta los factores biofísicos que han facilitado el desarrollo de las aglomeraciones humanas, con énfasis en aquellas intervenciones fisicoespaciales (incluyendo las electrónicas) que han propiciado la (des)localización y despliegue de actividades productivas y comerciales en el entorno urbano-regional y el papel que han jugado los actores clave que inciden en el modo de regulación.

- Aproximarnos a las lógicas y dinámicas de la acción colectiva en la región mediante las que se ha configurado la institucionalidad político-administrativa en la misma, ampliando el espacio de lo político más allá de los límites estatales y comprendiendo la política como una actividad mediante la que los actores sociales colectivos buscan concretar y defender sus imaginarios e intereses materiales bajo diversas formas que no necesariamente pasan por la representación política partidista.

- Identificar algunos de los conflictos territoriales asociados con las transformaciones físico-espaciales requeridas para darle fluidez a la acumulación capitalista en la región.

- Relacionar recíprocamente cada uno de los anteriores elementos entre sí, bajo la perspectiva de buscar si existe la configuración o no de un modelo de desarrollo territorial coherente en su capacidad de garantizar la integración social y su sostenibilidad sistémica, y en especial entender el modo en que se regula la lógica de acumulación capitalista territorialmente definida.

En esta dirección, pretendemos avanzar en los derroteros trazados por investigadores como Lipietz (1991), Hiernaux (1995) y Perkmann (s.f.) de especificar local y regionalmente las formas territoriales concretas que asume la reestructuración y la (des)regulación global de las relaciones productivas y de comer- 
cio, en cuanto el Estado-Nación como forma institucional dominante durante el fordismo, deja de ser cada vez más escenario de discusión y articulación de intereses colectivos, y pierde a su vez mayor capacidad de intervención en sus respectivas formaciones sociales de base, por lo que cede espacios y facilita la creación de nuevos escenarios en el ámbito de lo intra y supranacional.

Nuestros aportes buscan arrojar elementos que permitan comprender mejor la regulación de la economía y la sociedad en ámbitos regionales periféricos y su articulación específica con lo supranacional y global, en la medida que caracteriza las principales relaciones lógicas y dinámicas de producción material e interacción sociopolítica en la región y su impacto en la reconfiguración territorial de la misma.

Para entender la regulación de las relaciones y conflictos sociales y económicos de este entorno regional, se hace necesario definir no sólo la cadena productiva sino la relación entre ésta y la red de capital que teje parte de los hilos de la regulación en la región y que para lograrlo articula su propia red social. La interacción entre cadena productiva y la red social y empresarial del capital explica en parte la reconfiguración no sólo físico-espacial del territorio, sino la manera en que se conecta la red global, y los rasgos fundamentales del modelo de desarrollo que allí opera (véase el esquema I).

\section{Esquema I}

\section{Esquema teórico del desarrollo territorial}

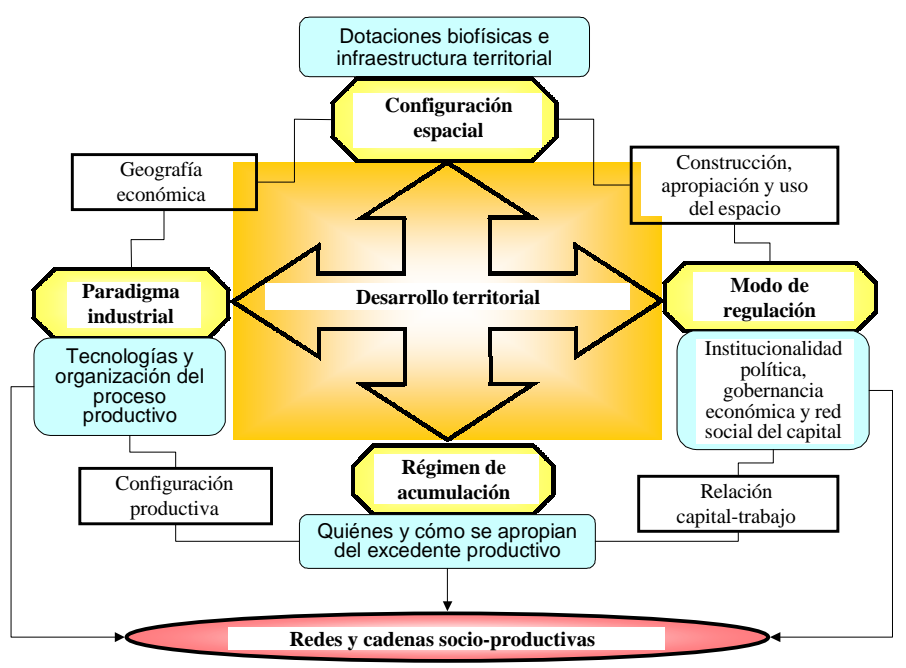




\section{Cadenas y redes productivas en un contexto de regulación excluyente}

Para analizar las cadenas productivas en la región urbana de Medellín y el Valle de Aburrá, tendremos en cuenta la manera en que la ciudad ha vivido los procesos de cambio económico, tanto por su dinámica propia, como por los impactos de las transformaciones en el patrón de acumulación y modelo de regulación en el ámbito global. En una primera parte trabajaremos como contexto las tendencias que en cuanto a desarrollo industrial y reconversión productiva se han identificado, para ello nos apoyaremos en trabajos realizados sobre este campo como los de Cuervo y González (1997) y el de Betancur (1995).

El concepto de cadena productiva lo ligamos al de desarrollo territorial (para nuestro caso urbano). En este sentido, no se circunscribe al sentido clásico de cadena sectorial, sino a la manera como se encadenan los factores productivos que generan riqueza o pobreza en la región, tanto desde el ámbito de la relación capital-trabajo, articulado al concepto de regulación y a la dinámica productiva, como desde la relación exclusión e inclusión socio-territorial articulada a la generación de tejido social y de equidad. Para ello serán claves en la cadena el papel y la estructura de las élites económicas, en tanto factores de poder y control de capital y la manera como ha impactado el proceso de globalización a las mismas, así como los nuevos encadenamientos que tejen y su impacto sobre el territorio.

\subsection{El contexto: un modelo de desarrollo industrial estancado}

Podríamos caracterizar al área metropolitana de Medellín y el Valle de Aburrá como "una región industrial en declive" (Méndez, 1997), al respecto es ilustrativo el siguiente planteamiento:

La crisis de Medellín traduce claramente el agotamiento de una fase de la industrialización colombiana basada en la industria textil y de confecciones. Sin embargo no se trata de un fenómeno única y exclusivamente técnico; es un proceso socioeconómico complejo. La crisis del tabaco en un momento y de los textiles en otro, ha dado lugar a la desaparición de ciudades y regiones prósperas. Sin embargo, en el caso de los textiles, la crisis de la producción antioqueña se ha acompañado de un cierto florecimiento en otros lugares, dando lugar a pensar que la obsolescencia no es solamente de una técnica o de un producto, sino de toda una forma de concebir la forma de competir, la manera de ser exitoso como empresario, de sostener pactos con los trabajadores y el resto de la sociedad. El análisis frío y escueto de las cifras y los indica- 
dores no agota la complejidad y profundidad de estos procesos. Hay que hacer el intento de comprender no sólo sus dimensiones estrictamente socioeconómicas, sino las mesoeconómicas, las que dan sustento a un patrón de industrialización exitoso. (Cuervo y González, 1997: 441).

Este planteamiento es clave, pues nos sitúa en las características generales del desarrollo económico de la región. Veamos entonces cómo ha evolucionado la región en esta dirección en las últimas décadas.

La dinámica económica y productiva de la región Medellín y el Valle de Aburrá se configuró hasta mediados de los 70 en un modelo de fordismo periférico ${ }^{2}$ que a partir de este periodo se rompe, lo que se expresa en un temprano proceso de desindustrialización, entendido como un estancamiento del modelo existente sin que empezaran a configurarse rasgos claros de un nuevo modelo de regulación. Este fenómeno puede explicarse en el peso que ha perdido la región en su posición industrial con respecto al resto de las áreas metropolitanas del país. ${ }^{3}$

Entre 1974 y 1991, mientras Bogotá, la ciudad capital de Colombia, incrementaba sus empleos industriales en 20,000, en Medellín se perdían 48,000 empleos, cuando antes de 1945 era la primera ciudad en generación de empleo manufacturero (Cuervo y González, 1997: 383).

Por otro lado, la dinámica industrial persistente conserva los rasgos del primer periodo de industrialización, basada en los bienes de consumo inmediato, algunos intermedios del sector textil y un estancamiento o pérdida de peso en el sector de bienes de capital, en este sentido se define a Medellín como un "centro nacional especializado", en la producción de textiles y confecciones. En el contexto de esta especialización también los indicadores permiten identificar la tendencia; al observar la participación de los sectores en el agregado industrial global se hace evidente cómo cinco de ellas muestran una pérdida acumulada de siete puntos porcentuales entre 1970 y 1990, éstos son: bebidas, taba-

\footnotetext{
${ }^{2}$ El concepto de fordismo que la escuela de la regulación ha retomado para explicar las características determinantes de las sociedades con alto desarrollo económico en un periodo de la acumulación capitalista (originado en lo que se ha definido como segunda revolución industrial), se ha nombrado como fordismo periférico para identificar la manera en que sobre un mismo paradigma de acumulación capitalista global se articulan las regiones del mundo que han sido denominadas como periféricas o dependientes. En ellas estarían incluidas las regiones que lograron un nivel significativo de desarrollo industrial, pero no consolidaron una institucionalidad que garantizara la regulación del modelo bajo los parámetros político y económico de los países más desarrollados.

${ }^{3}$ En general, me basaré en información trabajada por Cuervo y González (1997).
} 
co, confecciones, productos del cuero en el rango de bienes de consumo ligero y el textil como excepción en el sector de bienes de consumo intermedio. Como podemos observar, son la mayoría de estos productos la base de la especialización industrial de la ciudad.

\subsection{La cadena textil-confección: fuertes rasgos de debilidad}

A partir de los inicios de la década de los años ochenta, empezó a sentirse el declive de los sectores industriales tradicionales de la región como el textil, que pasó de representar el 30.88\% del total del valor agregado industrial de Antioquia en 1989 a 26.66\% en 1995, perdiendo más de cinco puntos en el lapso de seis años. Por el contrario, la agrupación de confecciones ha mostrado mayor dinamismo en este mismo periodo al aumentar su participación en el valor agregado de Antioquia para el mismo periodo en cinco puntos aproximadamente, al pasar de representar $4.11 \%$ en 1989 a $9.19 \%$ en 1995 . En cuanto a su participación en las exportaciones industriales, ésta pasó de representar 16\% en 1985 a 27\% en 1997 (Cámara de Comercio de Medellín, 1999).

Como principales exportadoras de confecciones entre 1996 y 1997 aparecen industrias como confecciones El Cid, Leonisa, Confecciones Colombia (Cámara de Comercio, 1999: 150); en el caso de El Cid, por ejemplo, produce a través de maquila y la totalidad de su producción es para exportación (véase gráfica I). Es necesario anotar cómo estas grandes exportadoras de confecciones, son a su vez las grandes importadoras de textiles (Cámara de Comercio de Medellín, 1999). En los análisis recurrentes sobre maquila se destacan las ventajas comparativas en costos de mano de obra, se afirma por ejemplo cómo mientras en Estados Unidos los costos por hora están entre 5 y 10 dólares, en Colombia están a 50 cts. de dólar en promedio, comparada con México, la mano de obra colombiana es entre $20 \%$ y $40 \%$ más baja que en dicho país. Llama también la atención la afirmación de Guillermo Valencia, presidente de industrias El Cid, acerca de cómo le han logrado arrebatar contratos a los chinos, cuando es bien conocida la competitividad de éstos por sus bajos salarios. ${ }^{4}$

${ }^{4} \mathrm{Al}$ respecto, véanse los Videos de momento empresarial, Cámara de Comercio de Medellín, Colombia, 026 Maquila 1 y co, 027 Maquila 2, octubre 5 de 1995. 


\section{Gráfica I}

\section{Comportamiento del comercio exterior de textiles Antioquia}

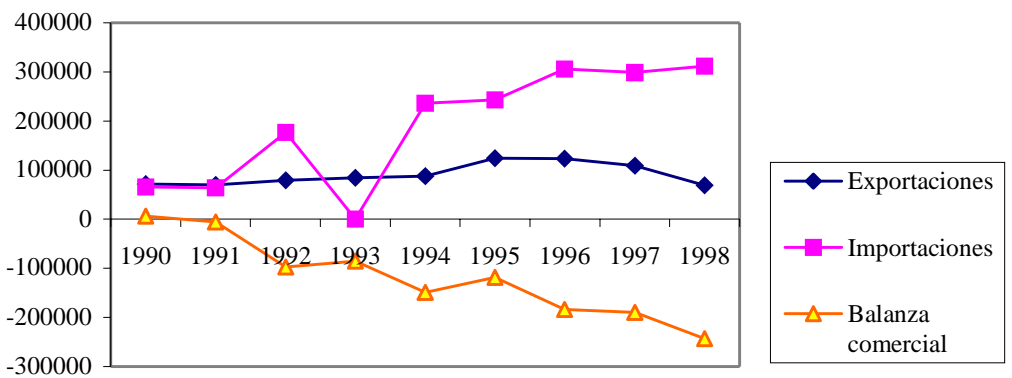

Fuente: Incomex, Manifiesto de aduanas y registros de importación. Tabulados: Cámara de Comercio de Medellín (Echeverri y Pulgarín, 1999: 39).

Lo que parece expresarse en estas tendencias del sector textil y de confecciones no es un encadenamiento que dinamice de modo global la economía de la región, pues como lo afirma un reciente estudio de la cámara de comercio de Medellín (La ventaja competitiva de la actividad empresarial antioqueña hacia el siglo XXI), parte del éxito del sector de confecciones se encuentra en que ha ganado independencia del sector textil, de manera que no lo han afectado sus recurrentes crisis; "más aún, el dinamismo del sector ha llevado a incrementar las importaciones de textiles, generando un déficit en su balanza comercial, frente a un superávit de la balanza de las confecciones" (p. 147).

El efecto mas significativo para la región ha sido la fuerte caída del empleo industrial, en el cuadro 1 vemos lo que pasó en las dos últimas décadas con el sector textil.

\section{Cuadro 1}

Personal ocupado y valor agregado de la industria textil en Antioquia

\begin{tabular}{|l|r|r|r|}
\hline & \multicolumn{1}{|c|}{1977} & \multicolumn{1}{|c|}{1996} & \multicolumn{1}{c|}{ Var. \% } \\
\hline Empleo & 42,712 & 23,780 & -44.32 \\
\hline $\begin{array}{l}\text { Valor agregado (\$ millones } \\
\text { constantes) }\end{array}$ & 2,709 & 2,348 & -13.29 \\
\hline Participación (\% empleo) & 35.20 & 19.00 & $-46 \%$ \\
\hline $\begin{array}{l}\text { Participación (\% valor } \\
\text { agregado) }\end{array}$ & 40.78 & 19.72 & $-51 \%$ \\
\hline
\end{tabular}

Fuente: DANE, Encuesta Anual Manufacturera (Echeverri y Pulgarín, 1999: 35). 


\subsection{Las confecciones: un modelo de producción excluyente}

Además de este aspecto en la cadena propiamente productiva, nos encontramos con un rasgo más preocupante, desde el punto de vista de las consecuencias sobre el desarrollo y la equidad. Las que destacamos acá como las grandes exportadoras de confecciones e importadoras de textiles, tejen a su vez una cadena productiva local basada en la explotación de una gran red de micro y famiempresarios, que en muchos de los casos se conectan desde la economía informal y generan empleos de muy baja calidad tanto en salarios como en condiciones de seguridad social. Podríamos entonces concluir que esta es una cadena globalizada que produce con base en una maquila difusa y que no se conecta con un proyecto de desarrollo equitativo a la economía local (véase gráfica II).

\section{Gráfica II}

Relación entre activos y empleo generado en empresas de confección a terceros en Medellín

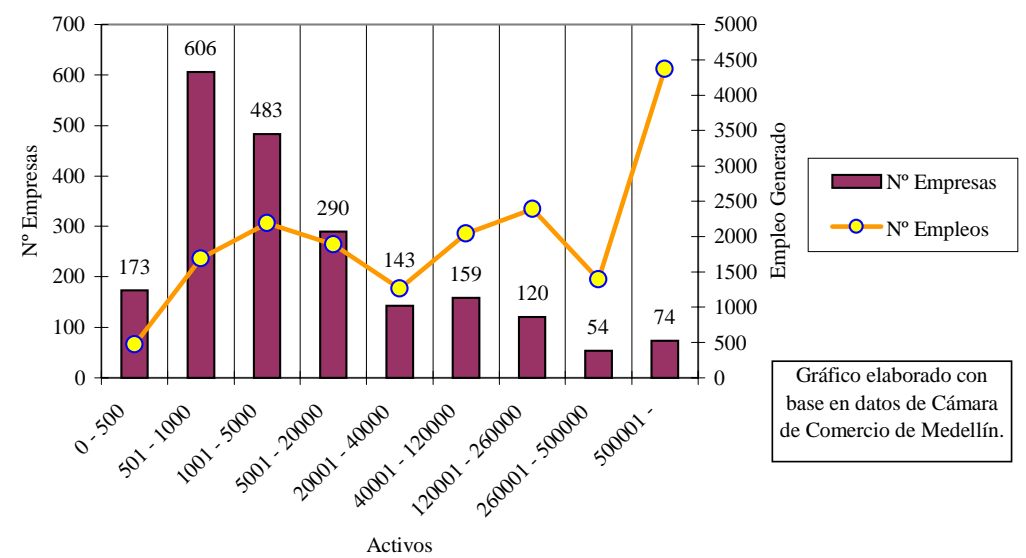

Fuente: Elaboración propia con base en información de la Cámara de Comercio de Medellín.

Si observamos la tendencia en los últimos años del Sindicato Antioqueño a incursionar en empresas como Leonisa, Confecciones Colombia o PMX, que por su dinámica parecen ser las controladoras de los volúmenes de exportación, al menos las dos primeras hacen parte de las nueve compañías que controlan el $60 \%$ de la exportación de confecciones en Antioquia, en el caso de Confecciones Colombia presentó un incremento en sus exportaciones 
de 46.25\% entre 1996 y 1997 (Cámara de Comercio de Medellín, 1999).

Se puede plantear cómo se está configurando un importante cluster de la confección basado en maquila, controlado por un pequeño número de empresas que concentran las exportaciones entre las que se encuentra la presencia del capital del Sindicato Antioqueño. Esto expresa una transformación de la relación capital trabajo, de una basada en contratación colectiva regulada por actores como el Estado Nacional, los sindicatos y los representantes del capital (empresarios), a una que más que flexibilizada es desregulada desde el punto de vista social, basada en la maquila, la subcontratación, el empleo flexible y los bajos salarios y en la que desaparece el modelo de negociación entre los actores que la regularon en las décadas pasadas. Ahora la relación capital trabajo toma la forma de relación entre empresas o entre capitalistas y empresas.

\section{Gráfica III}

Antigüedad de las empresas de confección a terceros en Medellín

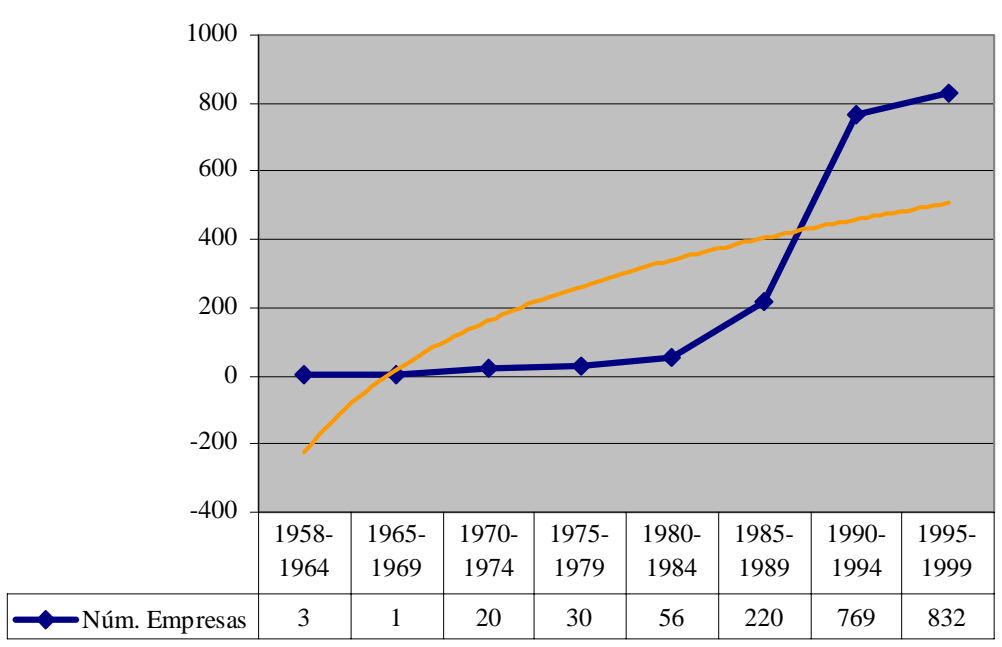

Fuente: Elaboración propia con base en información de la Cámara de Comercio de Medellín.

La gráfica III es la sistematización de la información sobre empresas de confección a terceros en Medellín entre 1958 y 1999. Lo que se observa es una tendencia creciente y disparada especialmente en la década de los noventa, del número de empresas registradas en la Cámara de Comercio de Medellín como confec- 
cionistas a terceros, sólo esta información nos muestra ya la importancia de esta relación capital trabajo y permite identificar los costos sociales de los cambios que de manera general se observan en las formas de regulación de la relación salarial en el sector textil-confección.

Esto ha llevado a que la relación entre economía formal e informal sea compleja y se hagan difusas sus fronteras, de la manera expresada por Pérez (1995), en la que un sector de la economía informal se conecta a la economía global en una tensión entre la inclusión y exclusión social y económica.

\subsection{El desarrollo industrial y sus efectos sobre la configuración territorial del Valle de Aburrá}

En el área metropolitana de Medellín y el Valle de Aburrá se pueden leer las huellas de la interacción entre economía y territorio y su impacto sobre la reconfiguración territorial de esta región urbana del Departamento de Antioquia en Colombia.

La dinámica industrial de la región desde inicios del siglo xx le permitió consolidarse como la primera región industrial del país hasta mediados del siglo, pero tanto la competencia de otras regiones y su dinamismo, como el caso de Cali y Bogotá, especialmente, la llevaron en las década posteriores, primero a compartir su primacía industrial con otras tres grandes ciudades de Colombia (Bogota, Cali y Barranaquilla) (entre la década de los sesenta y mediados de los setenta, especialmente), y después a bajar a un segundo lugar (el primero lo tomó Bogotá) compartido con Cali y Barranquilla (Cuervo y González, 1997).

A la par que se redefine su papel en el ámbito nacional, internamente la región también se reconfigura buscando sostener su competitividad en los ámbitos nacional y global. Esta reconfiguración se expresa en lo que definimos como tres tendencias de relocalización industrial en la región (Betancur, Stienen, Urán, 2001) veánse cuadro 2, mapa I, mapa II y esquema 2:

- La primera tendencia es de expansión hacia el Oriente antioqueño (especialmente el municipio de Rionegro), que inicia en la década de los sesenta, especialmente con la relocalización de empresas textileras basadas en un estudio hecho por los mismos empresarios, que les permitió identificar ventajas como costos laborales más bajos que en Medellín, mejor disposición del agua y bajos costos de la tierra, entre otros. Esta expansión se fue consolidando en la 
medida en que se alcanzaron las dotaciones infraestructurales necesarias como vías de acceso y la localización del aeropuerto internacional José María Córdoba en 1985. A la localización del aeropuerto está asociada la localización de la zona franca de Rionegro en 1995, que opera como zona franca privada operada por siete empresas, de éstas, cinco son del Grupo Empresarial Sindicato Antioqueño. Esta tendencia marcó dos fenómenos importantes: Primero reconvirtió la vocación productiva de la región de agrícola a industrial, y segundo, se ha convertido en una especie de expansión del área metropolitana de Medellín y el Valle de Aburrá.

- La segunda tendencia se refiere a la consolidación del sur del Valle de Aburrá como territorio privilegiado para la localización de la gran empresa y de las nuevas empresas de servicios que tienen importante componente de valor agregado. Garantizado en un primer momento (1940) por la canalización del río Medellín que habilitó los terrenos aledaños para la localización de gran industria y la dotación vial y de infraestructura adecuada para la producción y la distribución de las mercancías en el ámbito nacional. Y en un segundo momento por la línea de continuidad de esta dotación infraestructural para industrias de servicios como la dotación de tendidos de fibra óptica, entre otros. Su dinamismo se ha reflejado, en parte, en la expansión de la dinámica industrial tanto de micro, pequeñas, medianas e incluso grandes industrias hacia otros municipios ubicados en el sur del Valle de Aburrá. A la par los municipios del norte del Valle de Aburrá que mostraron dinámica importante en las primeras décadas del siglo xx, hoy muestran una tendencia de declive en la localización de actividades industriales.

- Por último se observa en el interior de la ciudad de Medellín un fuerte proceso de desconcentración y descentralización productiva, especialmente en lo referente al sector de la confección, como lo muestra la dinámica creciente de surgimiento de empresas de confección a terceros antes mencionada. 


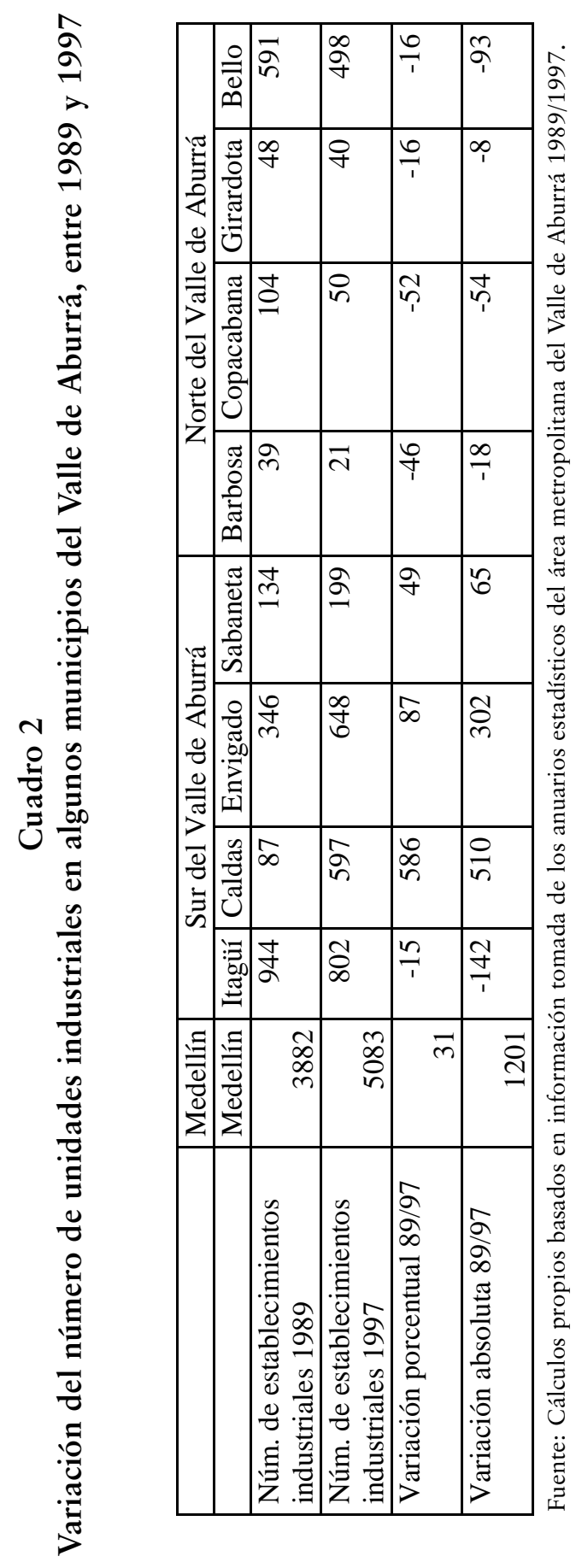




\section{Mapa I \\ Localización de Medellín y el Valle de Aburrá}

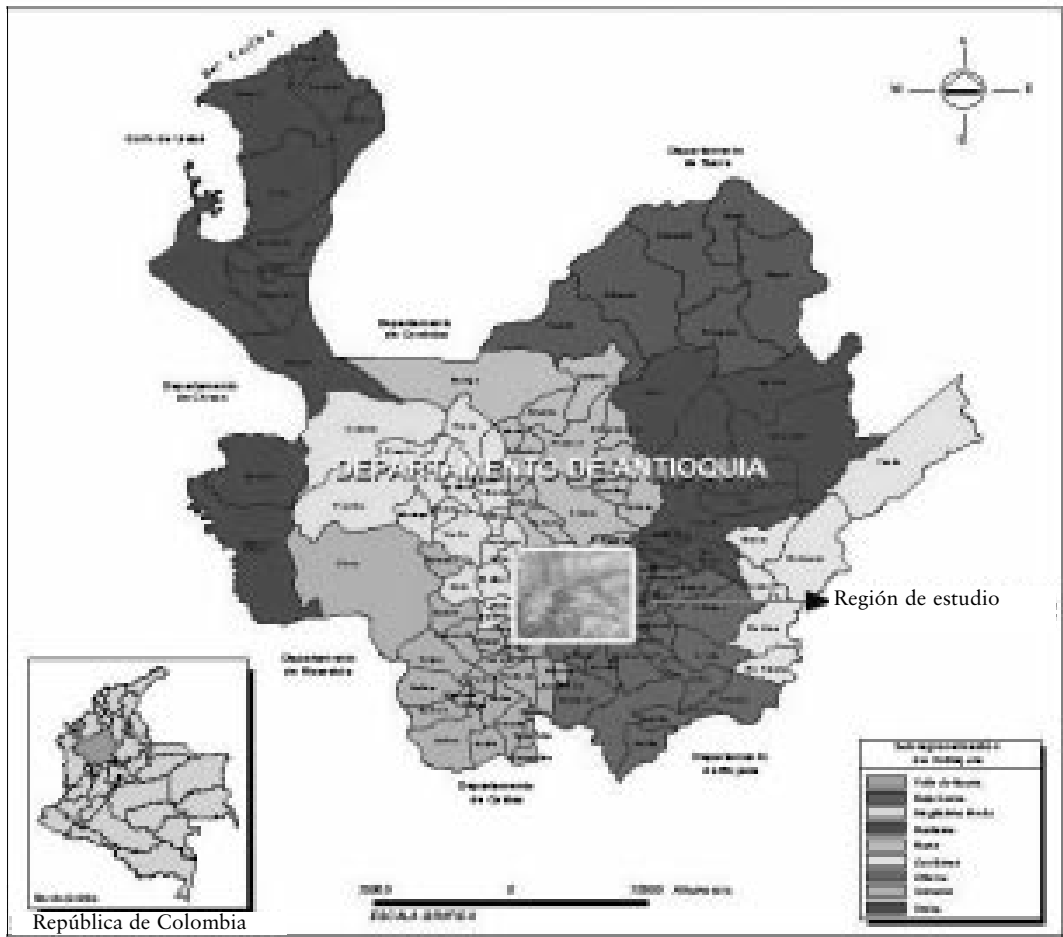

Fuente: Elaboración propia con base en mapa de la Secretaría de Planeación Departamental (de Antioquia). 


\section{Mapa II \\ Desconcentración regionalmente concentrada de la actividad industrial y productiva}

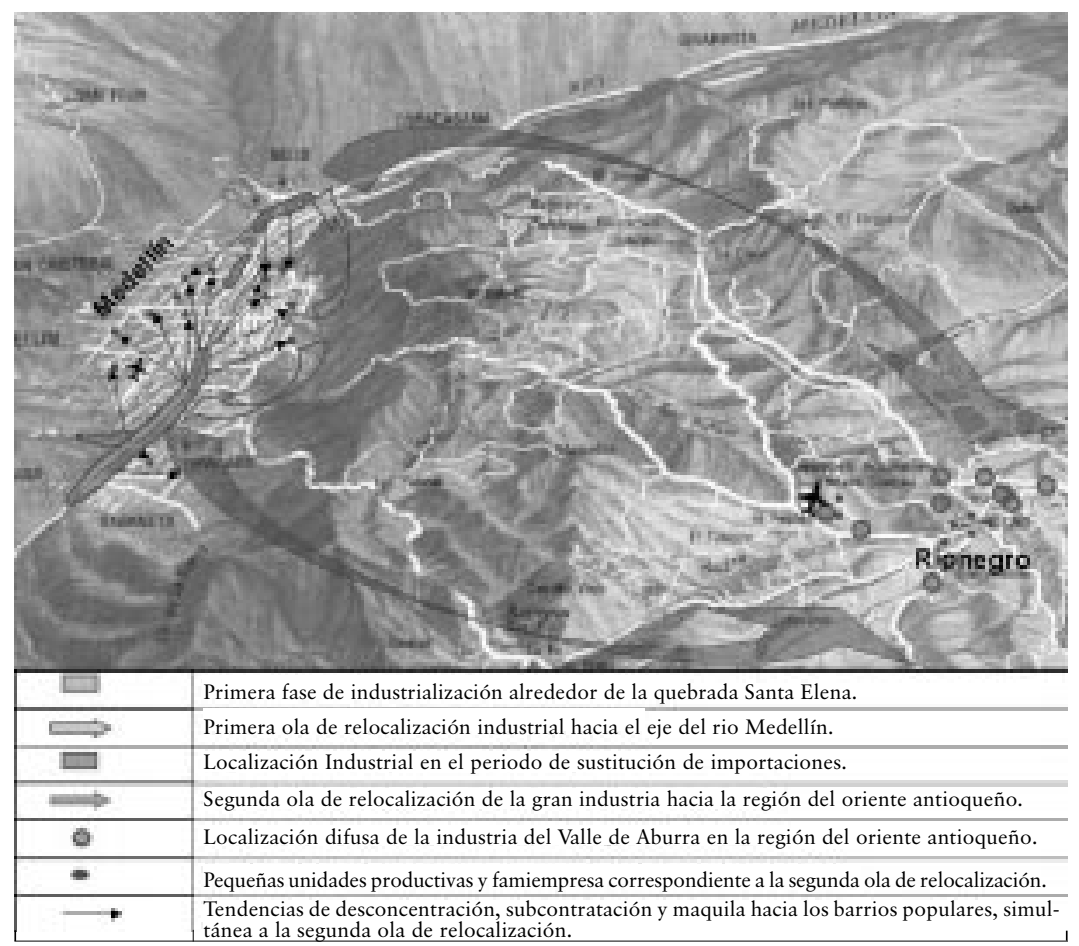

Fuente: Elaboración propia, con base en cartografía de Cornare. 


\section{Esquema II}

Corema de localización industrial Valle de Aburrá, década de los años noventa

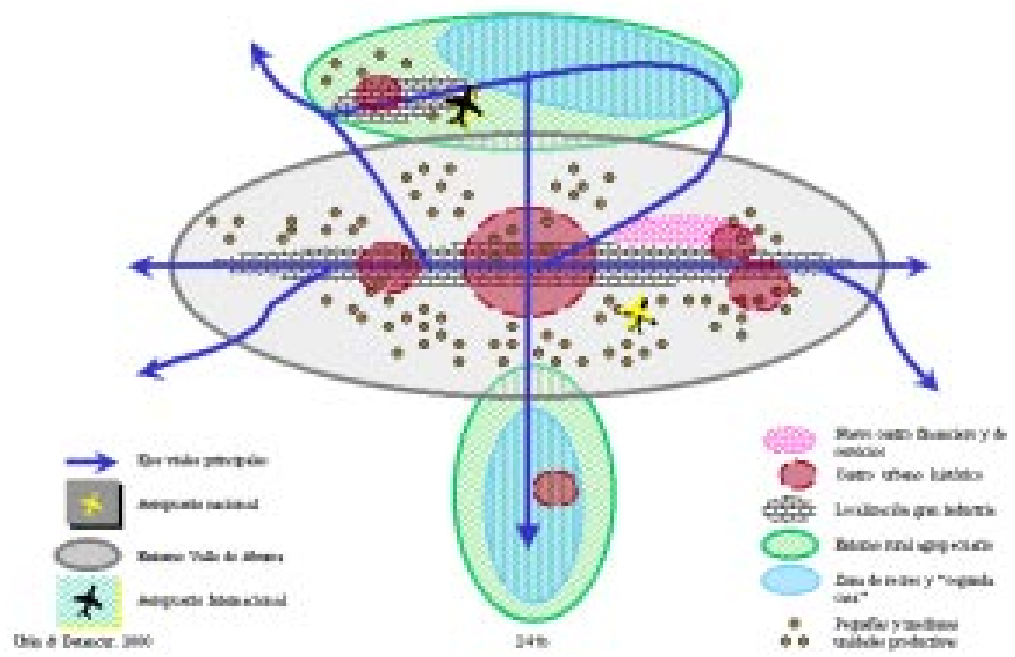

Fuente: Elaboración propia.

\subsection{La red social de los empresarios, una pieza clave en la} comprensión del modelo de desarrollo regional del Valle de Aburrá

En el departamento de Antioquia y particularmente en el entorno urbano-regional del Valle de Aburrá, el control de la red de capital económico tiene nombre propio, el Grupo Empresarial Sindicato Antioqueño. Su surgimiento como grupo económico ocurre a fines de los años setenta como estrategia de protección de las acciones de las empresas de la región que pretendían ser controladas por grupos económicos de la capital del país; este hecho les da un sello regional fuerte que se expresa en su nombre.

Se organizan en torno a una estructura compleja, una red basada en tres empresas que empieza a expandir su control a través de la compra de acciones de otras, de modo que a la vez que crecen y se expanden, configuran un poder regional anónimo. Esto hace que su apariencia sea más de una red de empresas, que de una red de capital. Su fuerte se mueve alrededor del negocio de los alimento con Noel y la Nacional de Chocolates a la 
cabeza, los cementos (con Argos) el negocio de los seguros y las finanzas con Suramericana de seguros. Estas empresas a su vez tienen el control accionario de otras tantas. Para ilustrar un poco el tipo de control que este grupo tiene en la región veamos el cuadro 3 acerca del control que los grupos económicos tienen de las 120 empresas más grandes de Antioquia.

\section{Cuadro 3}

Participación de los grupos económicos en las 120 empresas más grandes de Antioquia en 1995 (valores en millones de pesos corrientes)

\begin{tabular}{|l|r|r|r|r|}
\hline \multicolumn{1}{|c|}{ Grupo económico } & \multicolumn{1}{c|}{$\begin{array}{c}\text { Núm. de } \\
\text { empresas }\end{array}$} & Activo total & \multicolumn{1}{c|}{ Utilidades } & $\begin{array}{c}\text { Núm. de } \\
\text { personas } \\
\text { ocupadas }\end{array}$ \\
\hline Sindicato Antioqueño & 36 & $13^{\prime} 148,222$ & 517,654 & 50,347 \\
\hline Organización Ardila Lule & 12 & $3^{\prime} 266,814$ & 73,593 & 11,897 \\
\hline Grupo Santo Domingo & 6 & $2{ }^{\prime} 280,592$ & 69,684 & 6,326 \\
\hline Grupo Corona & 3 & 71,628 & $-4,436$ & 3,157 \\
\hline Grupo Cacharrería Mundial & 3 & 197,000 & 10,018 & 1,769 \\
\hline Grupo Bolívar & 1 & 38,899 & 1,052 & 206 \\
\hline Grupo Colpatria & 1 & 36,914 & 1,750 & 516 \\
\hline
\end{tabular}

Esta compleja estructura, que contiene toda la carga del regionalismo antioqueño, se ha convertido a la vez en una traba para el proceso de globalización de las empresas de la región como de la red de capital que controla su régimen de acumulación. Los capitales extranjeros temen negociar con un grupo de empresas de las que no saben, a ciencia cierta, quién maneja el control. De otro lado, las tendencias globales y los cambios en el papel del Estado, aunadas a la cultura rentista (Garay, 1999) de la región, han generado definiciones en torno al portafolio de inversiones del grupo empresarial, de tal modo que se define como estrategia el desinvertir en parte las inversiones que tienen que ver con el sector real de la economía, y abonar más inversiones al negocio más jugoso y del que ha salido el gran competidor: El Estado, los seguros en general, y en particular los negocios ligados a la seguridad social. Esta última es una de las estrategias más fuertes de globalización del capital controlado por el grupo empresarial antioqueño, especialmente en el ámbito de América Latina.

Según los datos obtenidos en la presente investigación, el grupo empresarial (Sindicato) Antioqueño ha configurado una compleja red donde se articula lo económico con lo social, fundamentalmente a partir de un doble proceso donde se combina la 
crisis industrial regional de finales de los años setenta con la amenaza de pérdida del control de las propias empresas por parte de otros agentes extrarregionales (véase esquema III). Este sentido de defensa, pero a su vez de necesidad de una profunda reconversión administrativa e industrial se expresará tanto en el entrecruzamiento de la propiedad (configurándose una comunidad social de intereses), como en el diseño y promoción de entidades externas al ámbito administrativo interno de cada empresa, pero claves en la gestión de sus relaciones con el entorno sociopolítico y el mercado laboral de la región. Es así como se entiende la activa participación de los ejecutivos de las empresas más importantes del sindicato en las juntas directivas de entidades sociales tipo organizaciones no gubernamentales (ONG) dedicadas al desarrollo regional y la gestión del empleo y la microempresa.

\section{Esquema III}

\section{Sindicato Antioqueño como red de capital económico y social}

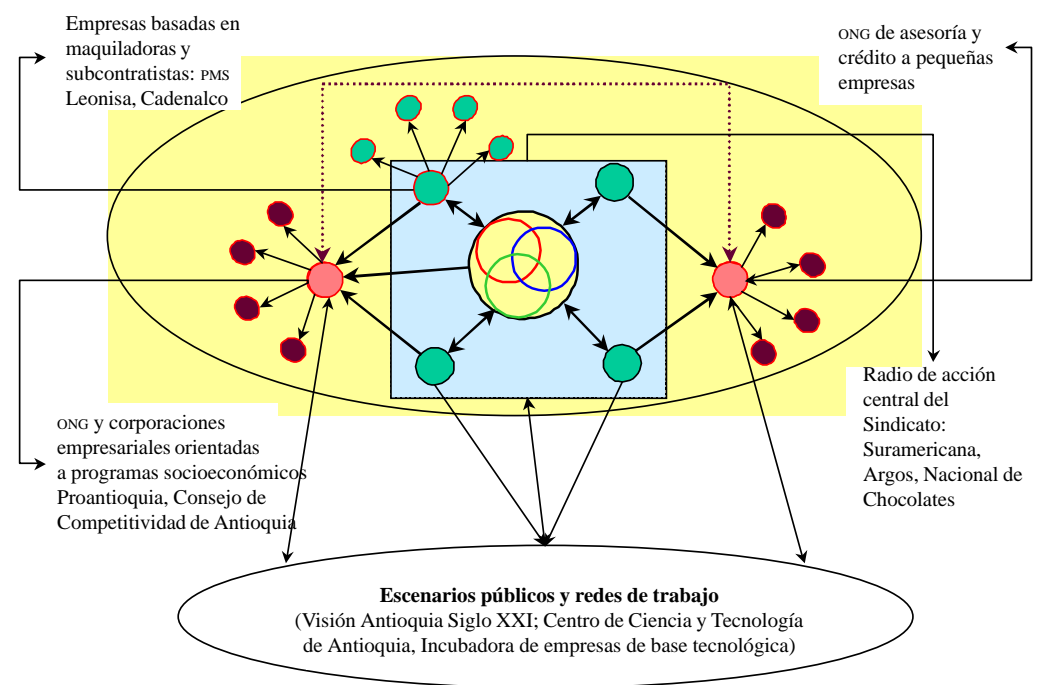

Fuente: Elaboración propia.

El papel de una organización social sin ánimo de lucro como Proantioquia, creada desde los empresarios, ha sido clave en la reconversión de la organización interna y lógica de interacción territorial política y socioeconómica del grupo empresarial Sin- 
dicato Antioqueño. Esta entidad, que ha actuado como especie de matriz social de este grupo empresarial, se ha destacado por vincular en su interior profesionales e investigadores de alto nivel que han cumplido un destacado papel en el estudio y configuración de políticas macro de desarrollo regional, las cuales van desde propuestas para la gestión del empleo y la producción en la ciudad, pasando por el apoyo a programas de ciencia y tecnología, así como de seguridad y convivencia ciudadana: iniciativas y proyectos, muchos de los cuales una vez en funcionamiento, se relacionan vía comercial o política con las empresas matrices del sindicato.

Como observamos en el esquema III, esta red de empresas a través de la que fluye el capital de la región, interactúa también en escenarios y redes donde confluyen otros actores, organizaciones e instituciones de la ciudad. La vitalidad e importancia de este tipo de escenarios (como el Plan Estratégico de Medellín y el Valle de Aburrá 2015, Visión Antioquia siglo xxI, o los planes zonales como mecanismos de interacción y construcción de ciudadanía en varias zonas y barrios de la ciudad de Medellín) se puede descubrir -y también su impacto en la regulación del desarrollo de la región- en la medida en que conozcamos cómo operan en ese proceso constante de interacción colectiva y de construcción de capital social en la región. Mostraremos algunos de estos aspectos en la segunda parte de este artículo.

\section{Proyecto de desarrollo territorial e interacción colectiva: construcción de capital social en un entorno de debilidad político-institucional}

Para acercarnos a la comprensión de la interacción entre redes de trabajo y acción colectiva con las principales redes y cadenas productivas en el área metropolitana, seleccionamos una muestra de los principales escenarios y redes de trabajo que han tenido lugar en el área metropolitana en la década de los noventa. En el análisis de estos escenarios se destacan los temas en pro y contra de su articulación práctica, acuerdos y conflictos, se destaca el alto grado en que se relacionan con la configuración y desarrollo territorial de la ciudad, en cuanto complejo socioespacial temporal en el que se yuxtaponen; y cómo interpenetran y transforman las escalas de lo barrial-local, lo comunal-municipal, lo municipalmetropolitano lo metropolitano-regional. 


\subsection{Descripción de los escenarios y redes de trabajo y acción colectiva, según actores y objetivos básicos de la acción}

Los siguientes escenarios son una muestra amplia que recoge los principales escenarios y redes de interacción que han participado activamente en los últimos cinco años en la construcción de políticas públicas para la ciudad, especialmente en los campos del desarrollo socioeconómico y territorial.

\section{Cuadro 4}

Redes y escenarios de interacción público-privado en Medellín y el área metropolitana

\begin{tabular}{|c|c|c|}
\hline $\begin{array}{c}\text { Escenarios-redes de participación } \\
\text { ciudadana }\end{array}$ & $\begin{array}{l}\text { Redes-escenarios mixtos estado- } \\
\text { empresa privada- organizaciones } \\
\text { sociales }\end{array}$ & Redes y escenarios privados \\
\hline $\begin{array}{l}\text { Veeduría ciudadana al plan de } \\
\text { desarrollo municipal (consejo rector) } \\
\text { Plan de desarrollo integral local } \\
\text { (parte alta zona centro-occidental de } \\
\text { Medellín) } \\
\text { - Mesa ciudadana de educación } \\
\text { - Plan alternativo zonal zona } \\
\text { nororiental } \\
\text { Plan de desarrollo zonal } \\
\text { participativo zona nor-occidental } \\
\text { - Plan local de desarrollo zona } \\
\text { centro-oriental } \\
\text { - Mesa ciudadana de espacio público } \\
\text { y territorio } \\
\text { - Mesa ciudadana de empleo }\end{array}$ & $\begin{array}{l}\text { - Plan estratégico de Medellín y el } \\
\text { área metropolitana } 2015 \\
\text { - Proyecto visión Antioquia siglo XXI } \\
\text { Corporación Concejo de } \\
\text { Competitividad de Antioquia } \\
\text { Centro de ciencia y tecnología de } \\
\text { Antioquia } \\
\text { - Sistema regional de innovación } \\
\text { (grupos de innovación) } \\
\text { Estrategia de ciencia y tecnología de } \\
\text { Medellín y Antioquia } \\
\text { - Incubadora de empresas de base } \\
\text { tecnológica } \\
\text { - Corporación Paisa Joven }\end{array}$ & $\begin{array}{l}\text { - Federación antioqueña de } \\
\text { ONG } \\
\text { ACIUR (Asociación } \\
\text { Colombiana de Investigadores } \\
\text { Urbano-Regionales) capítulo } \\
\text { Medellín } \\
\text { Proantioquia (Consejo } \\
\text { Directivo) }\end{array}$ \\
\hline
\end{tabular}

Los escenarios-redes mostrados en el cuadro 4 nos han servido para analizar, en términos de los actores que los integran y del sentido de su acción, la convergencia de sus objetivos, la tipología de actores predominantes en los mismos y su impacto agregado en la regulación y desarrollo territorial.

\subsection{Análisis de participación e implicación en los diferentes} escenarios y redes de trabajo, según actor y sector social, económico y político

La curva de distribución por frecuencias de la interacción y participación de los actores sociales en los diversos escenarios y redes de trabajo en donde se configuran políticas públicas para la ciudad y sus entornos regionales, nos indica una alta concentración de los niveles de participación pública en un reducido grupo de actores sociales. Ello nos permite inferir unos bajos niveles de interacción, si se tiene en cuenta el total de los actores, lo que a su vez se puede traducir en una alta vulnerabilidad del capital 
social y la institucionalidad que allí se están cimentando si el rango total de actores con altos niveles de implicación y participación no logra incrementarse, y a su vez dotar de mayor legitimidad, vía institucionalidad de estos escenarios.

\section{Cuadro 5}

Análisis comparativo del grado de participación e involucramiento en los escenarios y redes de trabajo y acción colectiva según sector institucional

\begin{tabular}{|lcccr|}
\hline \multicolumn{1}{|c}{ Sector social } & $\begin{array}{l}\text { Número de } \\
\text { actores }\end{array}$ & Frecuencia & $\begin{array}{c}\text { Porcentaje de } \\
\text { participación }\end{array}$ & $\begin{array}{c}\text { Frecuencia } \\
\text { relativa de } \\
\text { participación } \\
\text { (f/n) }\end{array}$ \\
\hline $\begin{array}{l}\text { ONG privadas no } \\
\text { empresariales }\end{array}$ & 28 & 51 & 16,6 & 1,82 \\
\hline $\begin{array}{l}\text { Entidades estatales } \\
\text { gubernamentales }\end{array}$ & 19 & 46 & 11,2 & 2,42 \\
\hline $\begin{array}{l}\text { Universidades y centros de } \\
\text { educación técnica o superior }\end{array}$ & 9 & 37 & 5,3 & 4,11 \\
\hline Fundaciones empresariales & 16 & 34 & 9,5 & 2,12 \\
\hline $\begin{array}{l}\text { Gremios y entidades } \\
\text { privadas federativas }\end{array}$ & 14 & 31 & 8,3 & 2,21 \\
\hline Empresa privada & 19 & 23 & 11,2 & 1,21 \\
\hline Comfamiliares & 3 & 12 & 1,8 & 4 \\
\hline Cooperativas & 11 & 11 & 6,5 & 1 \\
\hline $\begin{array}{l}\text { Otros actores sociales y } \\
\text { comunitarios }\end{array}$ & 50 & 50 & 29,6 & 1 \\
\hline Total & 169 & 295 & 100 & 1,75 \\
\hline
\end{tabular}

Al hacer gráficos estos datos, podemos observar mejor la dispersión-concentración de la participación por sector social. 


\section{Gráfica IV}

Nivel de participación en escenarios y redes de interacción

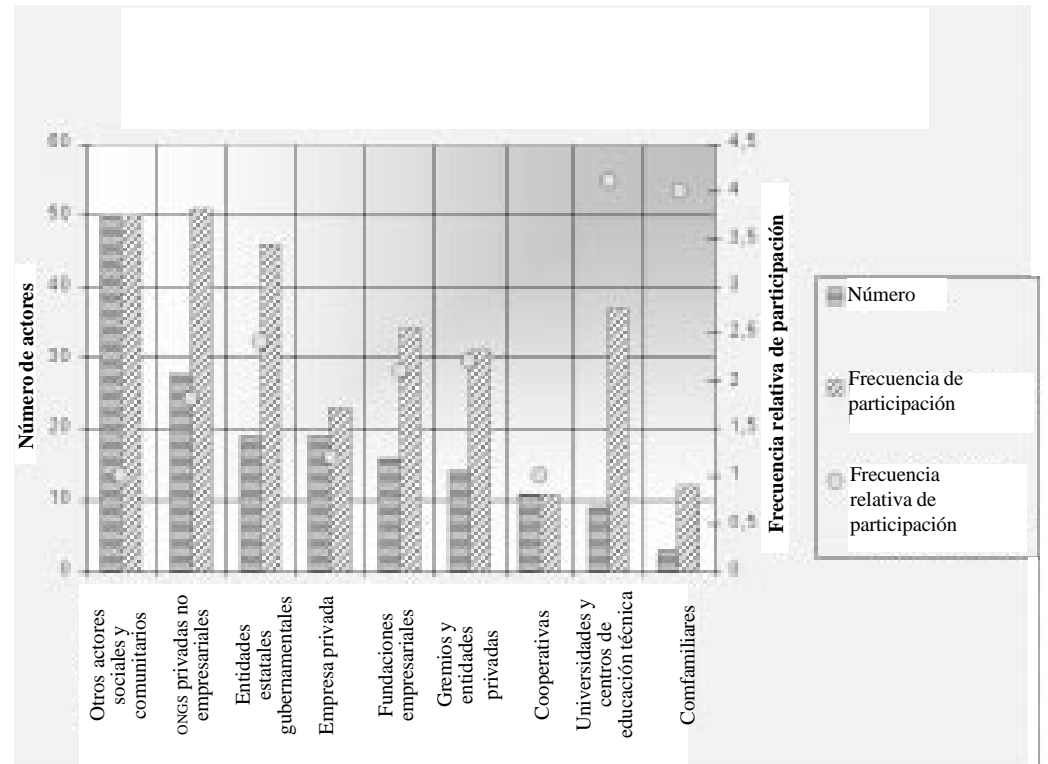

Fuente: Elaboración propia.

Como se puede observar en el cuadro 5 y la gráfica IV de síntesis anteriores, a nivel absoluto son las ONG no pertenecientes a la empresa privada y las entidades estatales las que más participan de los escenarios y redes de trabajo colectivo en la ciudad; sin embargo, en términos relativos, son las instituciones de educación superior y las cajas de compensación familiar (Comfamiliares) los actores que más participan de estas de redes y escenarios en términos numéricos. Ello permite afirmar que ciertamente la universidad no se encuentra desvinculada de su entorno sociopolítico, contrario a lo que recurrentemente se suele afirmar. Por otro lado, nos indica que si bien las ONG tienen una alta presencia en la ciudad, su capacidad individual de interacción es bastante débil, excepto un reducido grupo de las mismas que ha jugado un papel protagónico en la constitución misma de estos escenarios. Por su parte, las Comfamiliares, instituciones de carácter mixto, integradas por el Estado, los trabajadores y los empresarios, muestran una gran capacidad de interacción, reflejo a su vez de su búsqueda por incidir en la construcción de políticas públicas en el campo socioeconómico y cultural en la ciudad, configurándose como actores clave al respecto. 
En síntesis, en el análisis de la participación según actores, nos encontramos con que las universidades públicas y las Comfamiliares, a pesar de su escaso número son altamente participativas en los escenarios públicos, mientras que el Estado (en sus diferentes ámbitos territoriales de competencia) si bien su participación agregada es bastante significativa, la misma se hace bastante difusa cuando se tiene en cuenta la diversidad de organizaciones que lo representan. Ello difiere con respecto a las ONG de origen no empresarial, que si bien a nivel del número de organizaciones representadas es el más alto, su representación se encuentra bastante concentrada en dos de estas organizaciones. $\mathrm{Al}$ mismo tiempo, que las fundaciones empresariales presentan una distribución relativamente homogénea entre número de actores y frecuencia de participación.

\subsection{Objetivos e intereses de la acción según actores}

La revisión de los objetivos, misiones y visiones de estos escenarios nos lleva a concluir que son tres las tendencias fuertes que impregnan el sentido de la acción colectiva:

- El desarrollo territorial de determinada unidad socioespacial en específico: planes y estrategias de desarrollo en $z O^{-}$ nas y comunas, el área metropolitana y su entorno urbanoregional, así como para el Departamento y su entorno nacional.

- El impulso a actividades que relacionadas a la competitividad, tanto de las empresas como de la ciudad: red de ciencia y tecnología e incubadora de empresas.

- La participación política ciudadana y la apertura de espacios para la construcción de política públicas: veedurías y mesas de trabajo ciudadano.

No obstante, si bien existe convergencia en los objetivos, no es lo mismo en lo relativo a los sentidos e intereses. Los empresarios, en especial el grupo empresarial Sindicato Antioqueño, a través de sus organizaciones de desarrollo e investigación socioeconómica, ha buscado configurar políticas públicas que favorezcan la reconversión de sus industrias, flexibilicen las relaciones laborales y ayuden a expandir sus actividades, todo ello enmarcado dentro de la visión físico-espacial del desarrollo por ejes. Aquí, el interés es claro: conservar o mantener las tasas de rentabilidad y ganancia de sus empresas. Sin embargo, la tensión está en el cómo: 
reduciendo costos laborales o generando mayor valor agregado. Ambas soluciones tratan de probarse y ello se refleja en la relativa ambivalencia ante el proyecto de desarrollo regional impulsado.

Por un lado se presiona para que el Estado, a nivel nacional, flexibilice las relaciones laborales y reduzca los salarios para hacer más fácil las actividades de subcontratación y maquila, las cuales se fundamentan en fuerza de trabajo de baja calificación, lo que propicia el auge de un mercado de trabajo de bajo nivel educativo, poco creativo y poco competitivo a largo plazo; pero por otro lado, trata de propiciar el encuentro entre la universidad y las empresas en aras de incorporar tecnologías que mejoren e innoven en procesos y productos, lo cual precisa de la creación de redes de trabajo e innovación científica y tecnológica.

De allí que la ambivalencia radique en el mantenerse en un viejo esquema que prioriza la reducción de los costos laborales, tal como ocurre con las maquilas, o apostarle a un modelo basado en las sinergias entre trabajo asalariado, capital y conocimiento. Esto se deja observar en la poca implicación que han tenido los sindicatos en la definición de este proyecto de desarrollo regional, los cuales, fuera de ser los grandes ausentes en todos estos escenarios, no tienen a su vez propuestas claras para la redefinición de las relaciones laborales en el nuevo entorno globalizante.

Por su parte, la universidad pública viene redefiniendo desde hace varios años su relación con el sector productivo, en especial en lo que respecta a la creación de redes de investigación y centros de innovación, pero no posee una visión clara y de conjunto frente al modelo de desarrollo territorial, ello debido en gran parte a que la universidad, dado su carácter de institución del Estado no define por sí misma sus políticas estratégicas, sino que depende en un alto nivel de las políticas y planes oficiales, aparte de la heterogeneidad de personas y sectores sociales que en su interior dificulta tener una visión compartida sobre intereses y estrategias. En este orden de ideas, la universidad es un actor que a pesar de sus mostrados altos índices de participación, incide mas no define el modelo de desarrollo territorial.

Algo similar ocurre con las ONG no empresariales que al ser un basto sector compuesto por diversidad de organizaciones que van desde el trabajo educativo y social con niños y ancianos, la prevención de la drogadicción, la defensa de los derechos humanos, el medio ambiente, hasta la promoción de la democracia, les queda bastante difícil articularse como un solo actor, con posturas compartidas frente a la dinámica productiva y territorial de la 
ciudad. Sin embargo, es necesario destacar en tanto organismo de segundo grado a la Federación Antioqueña de ONG, que ha ido relevando el papel de estas instituciones y coadyuvándolas a tener un papel protagónico en la definición de políticas públicas, tanto urbanas como regionales, esto las acerca a configurar de manera más clara un 'sector social' con intereses claros en lo que concierne a la defensa de los espacios y escenarios de discusión y concertación de las políticas públicas, así como en la promoción de la justicia social. Si bien las bases económicas de este sector son aún bastante débiles en al ámbito local, sus agendas y financiamiento depende en gran medida de las agencias internacionales de cooperación y de las redes de trabajo de emigrantes. Todo lo cual le da un gran soporte político, técnico y financiero a sus actividades, y hace valer a éstas como actores con capacidad de incidir y tomar parte en la definición del modelo de desarrollo territorial.

Otro actor ligado por el sector al anterior son las cooperativas, las cuales presentan una muy débil participación, debido en gran parte a su escasa articulación como sector social, ello aunado a una carencia de desarrollo y actualización de las premisas cooperativistas, lo que hace que éstas sean relegadas a un segundo plano económico y político con pocas excepciones (como recuperar), que no bastan para que estos organismos se configuren como fuentes de innovación social y actores con peso político regional.

Es necesario resaltar el papel de las Comfamiliares, en cuanto actores mixtos entre la empresa privada, el Estado y el sector social, que poseen un papel de administrador de recursos financieros provenientes de las empresas y proveedores de diferentes tipos de servicios educativos, de salud y vivienda, principalmente, lo que ha hecho que estos actores tengan un peso relativamente alto en la definición de políticas públicas, muy en especial frente las relaciones laborales y a las políticas de salud. Lo anterior se refleja en la alta participación de estas instituciones en diferentes escenarios y las ha llevado a construir unos intereses bastante claros como gremio que cuenta con un gran respaldo ciudadano, tal como se ha observado frente a los intentos del gobierno y de un sector amplio de empresarios por abolir la fuente principal de sus recursos, llamados parafiscales, y que se constituyen en la transferencia de una parte del salario pagado por las empresas a estas entidades. De esta manera, lentamente, estas organizaciones han devenido en instituciones con alta legitimidad y capaci- 
dad de regular ciertos aspectos de la relación capital-trabajo, además de incidir notablemente en las políticas de desarrollo regional.

Por su parte, el Estado aparece como un actor sumamente fragmentado y sin coordinación entre sus diferentes ámbitos municipales, metropolitanos y departamentales, un poco a la saga de las iniciativas privadas o de las decisiones del ámbito nacional. De tal suerte que al ser el Estado, sobre todo en el ámbito urbano-regional, un complejo de organizaciones articuladas por intereses burocrático-partidistas poco relacionadas con la sociedad, pierde gran parte de su legitimidad y de su función reguladora de los conflictos e intereses sociales. Ello se debe, en gran parte, al aislamiento mismo y autonomización que los partidos políticos tienen frente a los otros actores sociales, han perdido gran parte de su función de representación de intereses e identidades y casi han devenido un fin en sí mismos. Ello se destaca en su falta de participación explícita en estos escenarios. Las consecuencias de este hecho son muy importantes para los objetivos de esta investigación: si el Estado se encuentra poco imbricado con los diferentes actores sociales y los partidos políticos no están articulando los diferentes intereses, ¿dónde se está regulando en el área metropolitana la tensión capital-trabajo-convivencia?

Ello nos conduce a observar en estos escenarios y redes de trabajo la formación aún precaria de cierta institucionalidad mediante la cual se tramitan y negocian diferentes intereses, lo que crea, a su vez, consensos mínimos sobre el futuro de la ciudad. Se trata de una conducción política global de la ciudad por fuera de los partidos políticos, los cuales de manera contradictoria con su función se gestionan y asumen como entes privados. Esto configura a su vez una amenaza y una oportunidad para el desarrollo de la competitividad y sostenibilidad sistémica del territorio metropolitano. Amenaza en cuanto a que los acuerdos que se logren en estos escenarios obtienen una muy baja institucionalidad y definición de política pública para su realización y seguimiento, y se ven sometidos a las inestabilidades y falta de visión estratégica de los partidos realmente existentes en el interior de la burocracia estatal. Oportunidad, en cuanto posibilidad de superar esquemas estadocentristas y avanzar hacia relaciones más fluidas y horizontales entre los diferentes actores sociales, lo que garantiza un nivel mesodinámico para el establecimiento de sistemas territoriales de innovación, en los cuales el Estado se asume como agente catalizador y no director exclusivo, del proyecto de socie- 
dad y territorio. Pero allí está el gran reto (problema) a superar: se requiere una recomposición en la burocracia y dirección del Estado a nivel municipal y metropolitano, para lo cual es preciso configurar nuevos movimientos o partidos políticos coherentes con el proyecto de desarrollo territorial prefigurado en estos escenarios.

El camino para ello está algo facilitado en la medida en que la continuidad de estos escenarios por varios años ha creado unos niveles básicos de confianza y sociabilidad política entre actores anteriormente distantes sociespacialmente y opuestos ideológicamente, tal como era el caso de un gran número de organizaciones barriales e intelectuales frente a los empresarios y el mismo Estado y viceversa. Pero este salto a lo político tiene su dificultad en la definición estratégica de un modelo estable de articulación y negociación entre el régimen de acumulación y la lógica de regulación de los conflictos y tensiones inherentes a éste, así como sobre el modo de producción territorial, cuestiones sobre las cuales aún no han avanzado estos escenarios y que necesita de la formulación urgente de propuestas por parte de los actores implicados antes que la confianza y capital social construidos empiecen a erodarse.

\subsection{Los planes de desarrollo local como configuración de capital social y riqueza territorial intraurbana}

Estos planes de desarrollo local son a su vez la cristalización de una histórica y compleja red de interacciones, de encadenamiento de subjetividades y necesidades materiales, en la que se articula una amplia gama de actores sociales y políticos provenientes de diferentes espacios y posiciones en la estructura social regional, entre ellos se destacan los programas de extensión universitaria, ONG comunitarias, instituciones laicas y religiosas, e instituciones macroempresariales (holding). Dichos planes son concebidos en su inicio como un aprendizaje de tecnologías de gestión del territorio para una planeación del territorio 'desde abajo', empero, en su proyección urbana devienen en mediadores de los diferentes sentidos y orientaciones de la planeación zonal y barrial, tanto por parte del Estado a su nivel municipal, como por parte de actores inscritos dentro de diferentes lógicas del conflicto armado (bandas delincuenciales y milicias urbanas).

En esta dirección, estos planes zonales devienen en un intento por construir tejido social en espacios urbanos donde la 
acción colectiva cooperativa ha sido escasa, poco racionalizada y orientada fundamentalmente hacia acciones de protesta y desintegración socioespacial. De allí el interés de los actores vinculados con estos planes por buscar configurar un marco político institucional que haga compatible los esfuerzos por crear una territorialidad local con aquellos otros esfuerzos por crear un territorio metropolitano incluyente y sostenible, como es el sentido dado por la mayoría de actores participantes en el Plan Estratégico 2015 para Medellín y el Área Metropolitana y que también orienta el apoyo y configuración colectiva de un sistema municipal de planeación como política pública.

No obstante, ello no se da sin tensiones. Desde la reflexividad de estos procesos de planeación zonal se destacan varias tensiones (Foro sobre Planeación Zonal, 1997), entre ellas:

- La concepción de planeación participativa altamente informal e instrumental por parte de los agentes del Estado, vs. la participación como construcción de tejido social por parte de los actores sociales no estatales allí implicados.

- Los ritmos y temporalidades de los actores comunitarios vs. los ritmos de la planeación político-administrativa.

- El énfasis en los resultados inmediatos por parte de los entes gubernamentales $v s$. el proceso sostenido y sostenible por parte de los actores sociales.

- Legitimación del Estado local, vía cooptación de los procesos de planeación zonal, vs. aumento de la capacidad de negociación y autogestión de las comunidades y organizaciones sociales zonales.

Entre las propuestas de ciudad construidas en la interacción de estos procesos y escenarios de planeación zonal se destacan:

- Programa económico integral y solidario contra el desempleo y fortalecimiento de las pequeñas y medianas empresas;

- Estrategia urbana integral para la paz y la convivencia;

- Políticas y planes de reubicación concertados con las comunidades afectadas por proyectos de infraestructura física;

- Fortalecimiento de las organizaciones de base, especialmente juvenil.

Como se puede observar, estos planes zonales, como procesos surgidos desde las redes de barriales mismas en su interacción 
horizontal no subordinada con otros actores tanto de la misma área metropolitana como del ámbito de la cooperación y solidaridad internacional, configuran una gran fuente de riqueza y capital social, que con la ayuda técnica y el apoyo socioeconómico de ONG de mayor envergadura, buscan construir territorios incluyentes articulados a la dinámica social, cultural y productiva de la ciudad, y que se contraponen a la acción local de los grupos armados que tienden a radicalizar la demarcación de fronteras y a propiciar la fragmentación territorial.

\subsection{La élite empresarial y su indefinición interactiva en la construcción social de un sistema territorial de innovación}

La crisis de integración social agudizada a finales de los años ochenta sirvió para que los principales grupos empresariales de la región se cuestionaran su enfoque tradicionalmente asistencialista benefactor y comenzaran a participar a través de sus fundaciones y organizaciones en proyectos de mayor implicación social. En esta dirección, es clara la amplitud estratégica de ONG de origen empresarial como Proantiquia, las cuales pasaron de pensar inicialmente proyectos e iniciativas orientadas directamente al desarrollo económico y a la infraestructura de soporte industrial, a participar en escenarios con una mayor orientación de política social, donde el enfoque pasa de ser puntual y asistencial, a uno de proceso, inserción e impulso a redes y grupos de trabajo, tanto académico- investigativo, como de desarrollo social.

El encuentro de los empresarios y su organizaciones con actores sociales provenientes de otros segmentos de la estructura social se puede observar en su participación en diversos escenarios, tales como: la Veeduría Ciudadana al Plan de Desarrollo Municipal, el Plan Estratégico de Medellín y el Área Metropolitana, Planes de Desarrollo Barrial, Proyecto Visión Antioquia Siglo Xxi, Mesa Ciudadana de Empleo, Centro de Ciencia y Tecnología de Antioquia, y la Incubadora de Empresas de Base Tecnológica, entre otros. En esta participación de empresarios en redes y escenarios colectivos de acción pública es necesario destacar las empresas del grupo empresarial (Sindicato) Antioqueño como las de mayor participación, tal como se muestra en la matriz de análisis comparativo del grado de participación e involucramiento (véase el cuadro 5).

No obstante, esta creciente participación en escenarios sociales por parte del sector empresarial contrasta fuertemente con 
un impulso central a políticas laborales basadas en la reducción de costos salariales vía flexibilización laboral e integración vertical de pequeñas y medianas unidades productivas con muy poca participación en la definición de estrategias para su red productiva. Esto configura así un contrasentido respecto de la orientación de la acción colectiva a nivel del Valle de Aburrá y su entorno regional. Es decir: por un lado, mediante el impulso y apoyo a escenarios de configuración sociopolítica como son los planes estratégicos del área metropolitana, la estrategia de ciencia y tecnología, y el proyecto de visión del desarrollo regional, se impulsa un escenario de equidad, cualificación del talento humano y participación política; y por otro lado, desde la gestión concreta de la red empresarial existente se impulsan procesos productivos que poco fortalecen el tejido social y el desarrollo de habilidades cooperativas basadas en redes cognitivas.

En esta dirección, el modelo de flexibilización laboral impulsado desde las empresas y sus medios marcha en contravía de la construcción de una área sistema, en cuanto sistema territorial de innovación, tal como se enuncia desde los escenarios realmente existentes de visión y planeación estratégica en la región. En síntesis, la 'táctica' de las empresas para responder a los retos de la competencia global no corresponde con la estrategia de desarrollo regional definida.

\subsection{El estado municipal y metropolitano: debilidad innovativa $y$ falta de representatividad sociocultural}

Para que las posibilidades de un sistema territorial más complejo ambiental y económicamente se cristalice a partir las redes de trabajo e interacción social que se han configurado en la última década, falta que el Estado a niveles municipal y regional sea mucho más creativo y propositivo, si tenemos en cuenta que casi todas las iniciativas viables e innovadoras provienen del sector privado, sea empresarial o social. Con ello no se quiere decir que sea sólo el Estado el que asuma esta función, sino que mínimamente se coloque al nivel de la interacción de los otros actores, en tanto creadores de valor social. Ello inquiere directamente por el rol y calidad del talento humano, tanto desde los partidos políticos que acceden a la dirección de los órganos gubernamentales del Estado, como por los agentes técnicos que ingresan a la tecnoburocracia pública: en ambos se observa una marcada incapacidad propositiva que se retroalimenta mutuamente. 
En esta dirección, podemos afirmar que mientras la reconversión estratégica de las organizaciones sociales y la relativa apertura de los grupos empresariales para entender la ciudad como sistema abierto de interacciones socioeconómicas y culturales se está configurando como una fuente de riqueza y de sostenibilidad de la territorialidad metropolitana, la estructura político-administrativa de la ciudad, salvo contadas excepciones personales, no está agregando valor a estas nuevas relaciones, por el contrario, está destruyendo valor con su falta de apertura político-institucional y su correspondiente ausencia de diseños metodológicos apropiados para la gestión de organizaciones sociales complejas que interactúan en diversas redes de trabajo.

Esta baja capacidad para coordinar la acción social metropolitana se traduce en bajos niveles de representación política y sociocultural, como lo deja ver el sondeo de opinión realizado a pobladores de la ciudad en el transcurso de esta investigación, en el que para $42 \%$ de la población encuestada el área metropolitana no debería ser una sola ciudad, tendencia que se corrobora con los talleres realizados en el municipio de Itagüí, y el cabildo abierto realizado en el municipio de Envigado durante 2001.

De lo anterior se sugiere que el área metropolitana, en cuanto entidad político-administrativa no se corresponde institucionalmente con los esfuerzos realizados desde diversos escenarios de interacción por concebir el Valle de Aburrá y su entorno inmediato como una gran región urbana, asunto que si no es tomado en serio por la élite política y empresarial de la ciudad configurará un entorno más difícil para la construcción de redes interinstitucionales e intermunicipales que permitan dar el salto estratégico que se plantea sin generar nuevas exclusiones socioespaciales en los municipios conurbados en torno a Medellín.

Sin embargo, a pesar de dicha debilidad político-institucional municipal, se puede afirmar que la ciudad está avanzado hacia una forma diferente de gestión y regulación pública en la que existe un mayor involucramiento de las organizaciones sociales en la configuración de políticas públicas relevantes para la construcción social y sostenibilidad del territorio, en cuanto sociedad metropolitana. 


\subsection{Actores sociales: reconstruyendo relaciones locales y densificando la red global desarticulada en el ámbito nacional}

Una somera revisión de las fuentes de recursos económicos de los principales actores sociales vinculados con los escenarios de interacción y construcción pública metropolitana nos muestra que la mayoría de ellos movilizan apoyos económicos para sus programas y proyectos de diferentes agencias y fundaciones internacionales de cooperación técnica y social ubicadas mayoritariamente en Europa, Estados Unidos y Canadá. Sin esta cooperación, muchas de las ONG que se destacan como actores relevantes en los escenarios de discusión y construcción de políticas públicas en los ámbitos socioeconómicos y territoriales de la ciudad, no existirían actores que después de las universidades públicas y la administración municipal son los que cuentan a nivel individual con mayores niveles de participación e interacción social.

Pero esta cooperación internacional también se ha figurado esencial para la creación de corporaciones mixtas de asociación estatal, social y empresarial, como lo es Paisajoven, actorred que ha servido a su vez de plataforma para la transferencia de tecnologías sociales de la agencia alemana GTZ a la ciudad, a la vez que ha servido de escenario para la definición colectiva de programas y líneas estratégicas de actuación en torno a las problemáticas de la juventud y el empleo metropolitano.

De igual manera, ONG para el empleo impulsadas y apoyadas por la élite empresarial de la región, han intensificado cada vez más su búsqueda de recursos económicos en agencias internacionales de diferente tipo como la Agencia de Cooperación Española, Misereor (Alemania), Interamerican Foundation (Estados Unidos) y Unión Europea, entre otras. Lo importante que debe preguntarse aquí es: hasta qué punto sin esta cooperación internacional hubiese sido posible la configuración de escenarios y redes de trabajo como las que analizamos en el presente trabajo. Lo cierto es que la acción colectiva de múltiples actores sociales, inclusive barriales, se encuentra globalizada en la medida en que la supervivencia de la organización depende fuertemente de la gestión de recursos internacionales, ya que al interior de la región, la multiplicidad de ONG y la escasez de recursos por parte del Estado y los agente privados, hace casi imposible el financiamiento de una acción perdurable.

De este modo, a las redes de trabajo e interacción metropolitana se articula de una manera, casi siempre imperceptible, 
una vasta y densa red de relaciones globales no mediada por afanes de lucro, y que actúa como respaldo (backbone) de la participación sociopolítica de estas ONG. En esta dirección, dicho encadenamiento social entre lo local y lo global se configura como una poderosa fuente de riqueza social, en la medida que no sólo sirve para movilizar recursos monetarios, sino que se configura a sí mismo como una inmensa red de trabajo para el intercambio y producción de tecnologías para la interacción y construcción social, a la vez que apuntala la capacidad de resilencia de las redes locales. Está por observarse si las ONG de empleo vinculadas a la élite empresarial de la región aprovecharán estas relaciones como un puente para el intercambio de experiencias y políticas significativas para la comparación evaluativa y mejoramiento de las condiciones técnicas y sociales del empleo en la región, o ello se reducirá simplemente a una búsqueda oportunista de flujo financiero no ligada al impulso de una política de modernización reflexiva e implicante de las redes productivas a nivel regional y atada a esquemas de desarrollo basados en la flexibilización laboral, que conserve la dualidad tendencial entre inclusión social discursiva y exclusión económica concreta.

Esta dinámica de interacción socioespacial coincide en general con la intensidad y amplitud de las relaciones socioespaciales que sostienen las organizaciones y grupos soporte en varios conjuntos de interacción colectiva presentes en el área metropolitana, tal como se observa en el esquema IV.

\section{Esquema IV \\ Conjuntos de acción colectiva según espacialidad en Medellín y el área metropolitana}

Fuente: Urán (1999).
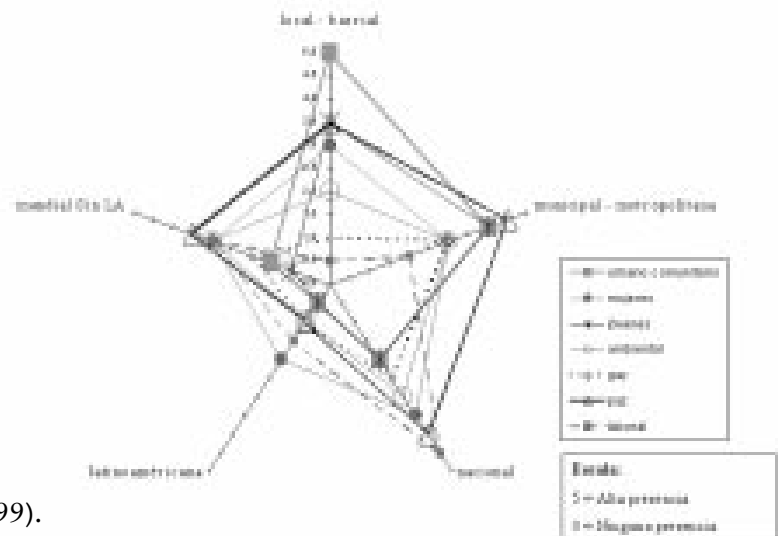


\section{Conclusiones}

\subsection{Concentración de la propiedad y especialización productiva como factor de desequilibrio social e inestabilidad territorial}

El cambio de patrón de acumulación a fines de los años setenta, aunado posteriormente a las políticas macro de apertura económica aceleró el proceso de desindustrialización en el Valle de Aburrá. Ello debido también en gran parte a la ausencia de políticas industriales, tanto en el ámbito estatal como en el de los propios empresarios, los cuales se habían acomodado al régimen proteccionista que les ofrecía una rentabilidad relativamente estable sin tener que esforzarse demasiado por diseñar estrategias sostenibles de competitividad. Esta transformación en la dinámica productiva transcurre en un contexto marcado por fuertes brechas sociales y políticas heredadas entre las empresas, las organizaciones sociales y las universidades, que no permitió crear un tejido de soporte en el cual se amortiguara la crisis económica.

Si a la marcada concentración oligopólica en la estructura de la propiedad regional se le articula el hecho de un marcado rompimiento con los vínculos sociales y cívicos que unían al empresariado regional con la construcción social y política de la ciudad antes de la década de los años cincuenta, nos encontramos con una estructura social fuertemente escindida, con unas muy débiles redes de cooperación transclasista a su interior, en la que lo social se reduce a las actividades de beneficencia y no se le concibe como la estructuración misma del soporte territorial en el que los conceptos de seguridad social, confianza, organización y redes de cooperación son clave para la sostenibilidad y equilibrio dinámico del territorio mismo. Esta falta de política social por parte del sector productivo, la que más tarde se denominará 'deuda social', agravará las condiciones generales de convivencia y productividad, en la medida que dé como resultado una generación de jóvenes desempleados, sin proyecto histórico (es decir, sin proyecto socioterritorial vinculante) y sin capacidades laborales para enfrentar adecuadamente los retos del nuevo entorno. De allí que no sea extraño que el Valle del Aburrá sea una de las área metropolitanas donde el desempleo estructural haya crecido y se haya mantenido por más tiempo en el país.

Empero, aun en la crisis existente, el cambio de mentalidad frente al funcionamiento de la economía continúa estando bas- 
tante centrado en los principios clásicos del acceso a factores naturales abundantes y los principios políticos de la regulación fordtaylorista. Lo anterior se traduce en una primacía de las políticas de desarrollo territorial orientadas a maximizar las ventajas geográficas y la dotación de recursos naturales en la región, lo que presiona a su vez al Estado en su nivel nacional a flexibilizar las relaciones laborales y reducir los costos salariales. Y si bien discursivamente ya se habla de fomentar la capacidad de desarrollo endógeno, y existen aproximaciones tímidas a la creación de redes de innovación territorial basadas en las relaciones cienciatecnología-producción y empresa-universidad-Estado, lo cierto es que no existe una clara orientación política regional al respecto ni una institucionalidad fuerte que respalde este proceso.

\subsection{Hacia una bifurcación de la trayectoria territorial socio- productiva}

En el área metropolitana del Valle de Aburrá, se observa la constitución de una cadena y red productiva socioterritorial altamente vertical, social y políticamente no implicante, que si bien puede generar la articulación de las élites empresariales locales al mercado global, no hace lo mismo con los otros actores sociales y productivos que componen la cadena y constituyen la red social amplia de agregación de valor y que son necesarios para una configuración territorial incluyente, equitativa y sostenible.

Estas redes y cadenas productivas, operan de manera descentralizada desde la producción, pero son centralizadas desde el control, gestión y comercialización por parte del capital. Se ubican espacialmente de una manera difusa en el Valle de Aburrá y el oriente cercano, corroborando así la tesis de una 'desconcentración concentrada' de la actividad productiva e industrial. Asociada a esta tipología de estructura red, se dan nuevas formas de pobreza difusa y no concentrada espacialmente, más ligada a la no existencia de capital social y cultural para acceder al capital productivo. El riesgo de incrementar la pobreza está en la consolidación del control de una cadena de valor por la élite empresarial con una estrategia de competitividad basada en reducción de costos laborales que profundiza la concentración de la riqueza en la región y genera poco capital cognitivo.

Esta lógica se explica en la manera como las élites políticas y económicas de la región han considerado lo social como algo meramente subsidiario de la actividad económica y sólo actual- 
mente se viene descubriendo su importancia estratégica en la construcción de formas sostenibles de desarrollo territorial. Pero igualmente, este cambio de escenario refleja a su vez un gran cambio en la lógica de la acción de las organizaciones sociales populares, las cuales de una dinámica orientada básicamente a la protesta se transforman hacia organizaciones propositivas y movilizadoras de recursos técnicos y económicos para el desarrollo tanto local como de la ciudad en su conjunto, lo que incrementa su participación y compromiso en la construcción de políticas públicas desde un punto de vista crítico pero dialógico, lo que configura una gran fuente de riqueza y sostenibilidad para el desarrollo urbano.

En el área metropolitana se observa, por lo tanto, una fuerte tensión entre un modelo de globalización territorialmente desestabilizador por parte de la elite empresarial y unas estrategias de construcción del territorio, en los ámbitos social, político y económico, por parte de una vasta red de organizaciones sociales, articuladas muchas de ellas a la cooperación internacional como forma de globalización no excluyente.

La ciudad se enfrenta al reto de articularse a la globalidad como conjunto integrado socioespacialmente desde dinámicas propias que garanticen unos altos márgenes de autonomía imbricada, tanto en lo económico como en lo político, o de ser articulada a macrointereses transnacionales teniendo como oferta exclusiva mano de obra barata, socialmente desarticulada y políticamente dependiente.

En el primer caso, con la reciente trayectoria de aprendizajes de los empresarios en cuanto a relacionar lo social y lo productivo, de las organizaciones sociales en cuanto a comprender mejor el lenguaje y la práctica productiva y empresarial, y de una necesaria fuerte reconversión del Estado para mejorar las capacidades y destrezas políticas y cognitivas de sus funcionarios necesarias para la interacción en escenarios múltiples, la ciudad y su entorno pueden avanzar hacia una configuración territorial espacialmente integrada, multisectorial y diversificada, en la que exista una difusión organizada y sistematizada del conocimiento social, con un sector financiero regional articulado estratégica y cooperativamente a las cadenas productivas con raigambre local, y una sociedad civil y un tercer sector fuertes que no descuiden en conjunto su entorno agrícola y rural con un criterio de sostenibilidad y resilencia territorial. 
En el segundo caso, de continuar las tendencias tradicionales, se profundizaría la segregación socioespacial y avanzaríamos hacia una nueva dualidad urbana de sectores conectados y sectores desconectados de la economía y la sociedad global, en este escenario el territorio se configuraría como un área productiva especializada, en la que primen las pequeñas empresas de subcontratistas en torno a unas pocas grandes empresas locales, que controlen el intercambio con el mercado externo y orientarían su acción hacia la reducción de costos salariales, minimización de costos burocráticos de transacción y maximización, a través del transporte, de su ventaja locativa frente a otros competidores externos. Se trataría, en todo caso, de una sociedad débilmente integrada y fácilmente vulnerable a los cambios del entorno global, dados los bajos niveles de articulación sociopolítica en su interior, su falta de articulación estratégica con el sector financiero y su carencia de preocupación por su entorno rural y agrario.

\section{Bibliografía}

Betancur, M.S. (1995), "La reconversión industrial y sus efectos sobre los trabajadores", Inédito, Instituto Popular de capacitación - IPC, Medellín.

—, A. Stienen, O. Urán (2001), Globalización, cadenas productivas y redes de acción colectiva. Reconfiguración territorial, nuevas formas de pobreza y riqueza en Medellín y el Valle de Aburrá, Tercer Mundo Editores, Bogotá.

Cámara de Comercio de Medellín (1999), "La Ventaja competitiva de la actividad empresarial antioqueña hacia el siglo xxı", Medellín.

Cuervo, L.; J. González (1997), Industria y ciudades en la era de la mundialización: un enfoque socioespacial, TM Editores, Col. Ciencias, Cider, Bogotá.

Echeverrí, J. y F. Pulgarín (1999), "Los clusters, una opción importante para Antioquia”, en Revista Antioqueña de Economía y Desarrollo, núm. 59, septiembre-diciembre, pp. $5-62$.

Fukuyama, F. (1998), Confianza: las virtudes sociales y la capacidad de generar prosperidad, Atlántida, Madrid. 
Garay, L.J. (1999), "La transición hacia la construcción de sociedad. Reflexiones en torno a la crisis colombiana", Santafé de Bogotá, marzo, (mimeo).

_ (s.p.i.), "Los sistemas de pequeñas empresas: un caso paradigmático de desarrollo endógeno".

Hiernaux-Nicolas, D. (1995), “Tiempo, Espacio y Apropiación Social del Territorio: ¿Hacia la Fragmentación en la Mundialización?”, Diseño y Sociedad, núm. 5, Primavera, Universidad Autónoma Metropolitana-Xochimilco, México.

Lipietz. A. (1991), "El mundo del postfordismo”, Ensayos de economía, núm. 12, Bogotá.

— D. Leborgne (1991), "Nuevas tecnologías, nuevas formas de regulación. Algunas consecuencias espaciales", en Revolución tecnológica y reestructuración productiva: Impactos y desafíos territoriales, Grupo Editorial Latinoamericano, Buenos Aires.

Méndez, R. (1997), Geografía económica. La lógica espacial del capitalismo global, Ariel Geografía, Barcelona.

Pérez Sainz, J.P. (1995), "Globalización y Neoinformalidad en América Latina”, en Revista Nueva Sociedad, núm. 135, Caracas.

Putnam, R. (1994), Para hacer que la democracia funcione, Editorial Galac, Caracas.

Repetto, F., (1998), "Notas para el análisis de las políticas sociales: una propuesta desde el institucionalismo", Perfiles Latinoamericanos, año 7, núm. 12, México.

Urán Arenas, O. (1999), Movimientos sociales y democracia en Medellín y el área metropolitana, IPC, Medellín.

Enviado: 21 de mayo de 2001 Aceptado: 30 de julio de 2001 
